\title{
Proteomic-based analysis for identification of potential serum biomarkers in gallbladder cancer
}

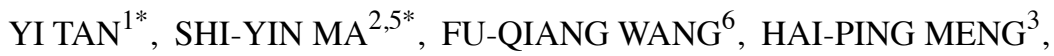 \\ CUIZHU MEI ${ }^{4}$, ANGEN LIU ${ }^{7}$ and HAO-RONG WU ${ }^{5}$
}

\begin{abstract}
Departments of ${ }^{1}$ General Surgery, ${ }^{2}$ Otolaryngology Head and Neck Surgery, ${ }^{3}$ Clinical Laboratory, First Affiliated Hospital, ${ }^{4}$ Department of Preventive Medicine, BengBu Medical College, BengBu, Anhui; ${ }^{5}$ Department of General Surgery, Second Affiliated Hospital, Suzhou University, Suzhou; ${ }^{6}$ Laboratory of Reproductive Medicine, Department of Histology and Embryology, Nanjing Medical University, Nanjing, Jiangsu, P.R. China; ${ }^{7}$ Tissue Biorepository, Hollings Cancer Center, Medical University of South Carolina, Charleston, SC, USA
\end{abstract}

Received March 4, 2011; Accepted May 16, 2011

DOI: 10.3892/or.2011.1353

\begin{abstract}
Gallbladder cancer is the most common malignant tumor of the biliary tract. Early diagnosis of gallbladder cancer is difficult because of the latent onset and lack of good biomarkers. To identify new biomarkers that improve the early diagnosis and/or serve as possible therapeutic targets in gallbladder cancer is essential. In the present study, serum proteins were separated by two-dimensional gel electrophoresis (2-DE) in 3 patients with gallbladder cancer and 3 healthy volunteers. The differentially expressed spots were identified by matrix-assisted laser desorption ionization time-of-flight mass spectrometry (MALDI-TOF-MS). Western blotting and immunohistochemistry were performed to verify the expression of certain candidate proteins. Protein expression and clinical correlation was evaluated. We found that 64 protein spots were significantly changed in gallbladder cancer. Twenty-four proteins including S100A10, haptoglobin, cystatin-B, profilin-1 and superoxide dismutase were successfully identified. Among these proteins, S100A10 and haptoglobin were validated using Western blotting. Immunohistochemically, the expression of S100A10 and haptoglobin proteins was found to be higher in gallbladder cancer tissues compared to that in gallbladder adenoma, liver cholangiocarcinoma and cholecystitis tissue. Patients with high expression of S100A10 and haptoglobin
\end{abstract}

Correspondence to: Dr Hao-Rong Wu, Department of General Surgery, Second Affiliated Hospital of Suzhou University, Suzhou 215000, P.R. China

E-mail: tmjtx2009@163.com

Dr Angen Liu, Tissue Biorepository, Hollings Cancer Center, Medical University of South Carolina, Charleston, SC, USA

E-mail: liuan@musc.edu

*Contributed equally

Key words: gallbladder cancer, serum proteomics, S100A10, haptoglobin, two-dimensional gel electrophoresis were linked to late stage disease and poor clinical prognosis. Our data suggest that combined comparative proteomic analysis by 2-DE and MALDI-TOF-MS is an effective method for identifying differentially expressed proteins in serum samples. These proteomic approaches could be used for identifying new serum biomarkers in gallbladder cancer. S100A10, haptoglobin and other identified proteins may be potential molecular targets for early gallbladder cancer diagnostics and therapeutic applications.

\section{Introduction}

Gallbladder cancer is the fifth most common cancer involving the gastrointestinal tract and the most common malignant tumor of the biliary tract worldwide. Gallbladder cancer is traditionally considered as a highly lethal disease with a less than 5\% of overall 5-year survival (1). Early detection and proper treatment are the most effective means to reduce the gallbladder cancer mortality. Of all the treatments of gallbladder cancer, surgical resection offers the best outcome. However, at the time of diagnosis, approximately half of the patients already have metastases. One-third of patients are diagnosed as local advanced gallbladder cancer, whereas only a small proportion, less than $20 \%$ of patients are eligible for surgery (2). Since most symptoms related to this malignancy can only be seen when the disease has advanced and unresectable stage, the early diagnosis of gallbladder cancer remains challenging. Although the serum tumor marker CA19-9 has been widely used in the diagnosis of gallbladder cancer, it is neither sufficiently sensitive nor accurate, and cannot be used for screening the early stage of gallbladder cancer (3). There is an urgent need to develop an effective screening system for asymptomatic individuals and to improve the diagnostic accuracy for gallbladder cancer at the early stage.

In recent years, the rapid development of proteomics technologies has provided technology platforms to find new cancer biomarkers. Two-dimensional gel electrophoresis (2-DE)-based comparative proteomic analysis has been applied successfully to screen potential biomarkers for many cancers 
using cancer cell lines $(4,5)$ and tumor tissues $(6,7)$. However, compared to blood samples, cell lines and tumor tissues are not clinically useful or convenient, especially for cancer screening and early diagnosis.

In the present study, we performed 2-DE and matrixassisted laser desorption ionization time-of-flight mass spectrometry (MALDI-TOF-MS) analysis to screen potential serum biomarkers for the early detection of gallbladder cancer in a Chinese population. We compared the gel images from the gallbladder cancers group with those from healthy volunteer group, and identified a group of differentially expressed proteins. Two newly identified proteins, S100A10 and haptoglobin were further subjected to Western blot and immunohistochemical analysis, and were validated as potential gallbladder cancer biomarkers.

\section{Patients and methods}

Patients and samples. Patients' serum and formalin-fixed paraffin-embedded tissue specimens were obtained from the Department of General Surgery and Pathology, the Second Affiliated Hospital of Suzhou University (Suzhou, China). Informed consent was obtained from all study subjects with the approval of the Committee on Clinical Investigation of the Suzhou University, which was in accordance with the ethical standards as formulated in the Helsinki Declaration of 1975 (revised in 1983). Serum samples were collected from 9 patients with gallbladder cancer. The patients were 5 males and 4 females, with ages ranging from 51-78 (median, 65) years. All patients had a resectable tumor, and no lymph node or distant metastases at the time of diagnosis. Serum sample from 9 healthy volunteers who provided consent form were also collected and used as control group. The healthy volunteers were selected from cancer-free people who receive regular check-ups and cancer screening tests. The healthy volunteers in this study consisted of 6 males and 3 females, with ages ranging from 50-70 (median, 60) years. All blood samples were collected in the morning before breakfast. The blood samples from cancer patients were collected prior to any treatment. Five milliliters of whole blood were obtained and stored at $4^{\circ} \mathrm{C}$ for $1 \mathrm{~h}$, then centrifuged for $10 \mathrm{~min}$ at $3000 \mathrm{rpm}$. Serum samples were then pooled, aliquoted and stored at $-80^{\circ} \mathrm{C}$ until analysis. Serum samples from 3 gallbladder cancer patients and 3 healthy volunteers were subjected to 2-DE and MALDI-TOF-MS analysis. Serum samples from the other 6 gallbladder cancer patients and 6 healthy volunteers were subjected to Western blot analysis. In addition, formalin-fixed, paraffin-embedded tissue blocks from 50 cases of gallbladder cancer, 20 cases of gallbladder adenoma, 20 cases of normal gallbladder tissue, 5 cases of liver cholangiocarcinoma and 5 cases of cholecystitis were also collected and subjected to immunohistochemistry.

Removal of high abundance proteins from serum samples. Fifty microliters of the pooled serum samples from gallbladder patients and healthy volunteers were processed with the ProteoExtract ${ }^{\mathrm{TM}}$ Albumin/IgG Removal Kit (Calbiochem, San Diego, CA, USA). Using this kit the albumin and IgG can be selectively removed from the serum sample. The excessive salts were removed by precipitation of proteins using the
ProteoExtract ${ }^{\mathrm{TM}}$ Protein Precipitation Kit (Calbiochem). All samples were processed according to manufacturer's instructions. The protein concentrations of the serum samples were determined by the Bradford method (Bio-Rad Protein Assay; Bio-Rad Hercules, CA, USA).

Two-dimensional gel electrophoresis. Serum samples were subjected to 2-DE as described previously (8). Briefly, IPG strips (24 cm, pH 3-10, NL; Amersham Bioscience, Uppsala, Sweden) were rehydrated with $80 \mu \mathrm{g}$ solubilized protein (for silver staining) in rehydration buffer. After isoelectric focusing, the IPG strips were equilibrated. Subsequently, the IPG strips were loaded onto pre-cast $12.5 \%$ homogeneous polyacrylamide gels for electrophoresis. The gel was ran in the Ettan-Dalt II system (Amersham Biosciences, San Francisco, CA, USA) and visualized as described previously (8).

Image acquisition and analysis. The silver stained gels were scanned, and resulting images were analyzed using the ImageMaster $^{\text {TM }}$ 2D Platinum Software (Version 5.0, Amersham Bioscience, Swiss Institute of Bioinformatics, Geneva, Switzerland) for spot detection, quantification, as well as comparative analyses, as described previously (9). Triplicates of 2-DE gels from each sample were produced to minimize run-to-run variation. ImageMaster software was used to measure the protein expression level of each sample. The relative intensities of spots were used for comparison between gallbladder cancer groups and healthy groups, respectively. The common differentially expressed spots (2-fold increase or decrease), as determined by the above comparisons, were further identified by MALDI-TOF-MS (10).

In-gel tryptic digestion and MALDI-TOF MS. Each of the common differentially expressed spots was excised from the gels, and dehydrated with $50 \mu \mathrm{l} \mathrm{ACN}$ for $5 \mathrm{~min}$ at room temperature. After incubated in $50 \mu \mathrm{l}$ of $10 \mathrm{mmol} / \mathrm{l} \mathrm{DTT}$ at $56^{\circ} \mathrm{C}$ for $1 \mathrm{~h}$, the spots were then incubated in $50 \mu \mathrm{l}$ of $55 \mathrm{mmol} / 1$ iodoacetamide at room temperature in the dark for $45 \mathrm{~min}$. Subsequently, the spots were dehydrated with $50 \mu 1$ ACN, rehydrated in $5 \mu 1$ porcine trypsin for $30 \mathrm{~min}$. Proteolysis was conducted by adding $10 \mu \mathrm{l}$ of $25 \mathrm{mmol} / \mathrm{l}$ ammonium bicarbonate, incubation overnight at $37^{\circ} \mathrm{C}$, stopped by adding $10 \mu 12 \%$ formic acid and desalted using C18 Zip Tips. The resulting peptides were concentrated, mixed with a-cyano-4hydroxycinammic acid (a-HCCA, Sigma, St. Louis, MO, USA), and then deposited on a 384-well MALDI target until air dried. Analyses were performed using a Biflex IV (Bruker Daltonics, Germany), as described previously (8).

Mass spectra interpretations and database searches. Peptide mass-fingerprint was used for protein identification from tryptic digested fragment sizes. Based on the Swiss-Prot protein database, the Mascot search engine (http://www.matrixscience. com) was used for database search. Up to one missed trypsin cleavage was allowed, although most matches did not contain any missed cleavages. Mass tolerance of 100 ppm was the window of error to be allowed for matching the peptide mass values.

Western blotting. Western blotting was performed as described previously (9). Briefly, the protein concentrations was firstly 
A

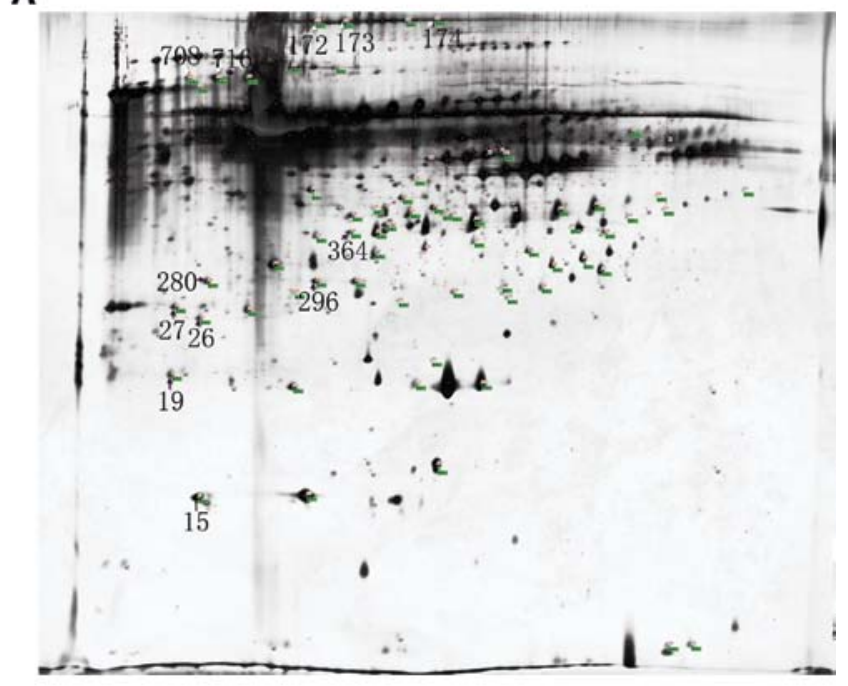

B

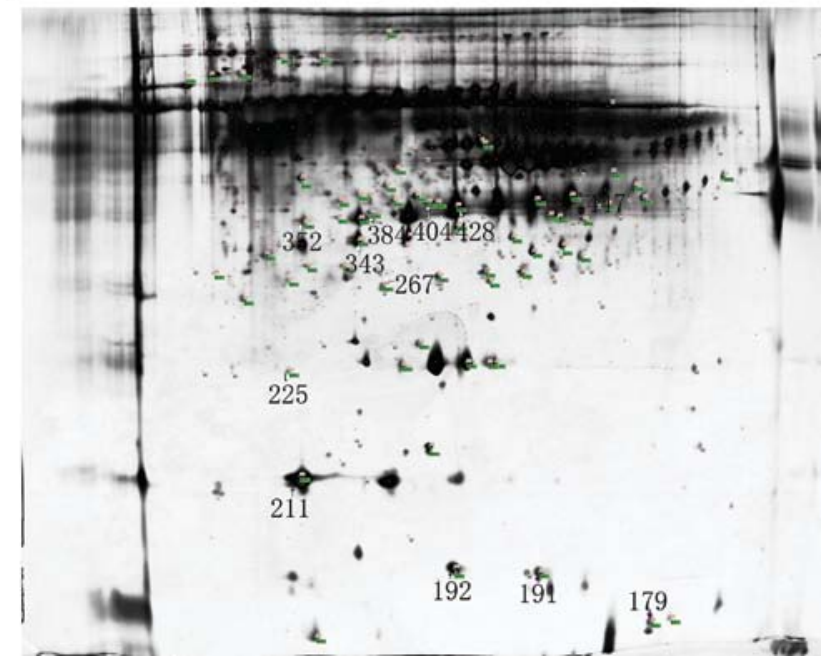

Figure 1. Serum protein expression profiles analyzed by 2-DE in gallbladder cancer patients (A) and healthy volunteers (B). Twelve overexpressed protein spots in gallbladder cancer were labeled.

measured using the Bradford assay, and $20 \mu \mathrm{g}$ protein/lane was resolved on $12.5 \%$ SDS-PAGE. The resolved proteins were transferred onto a nitrocellulose membrane. Blots were blocked in PBS containing $0.05 \%$ Tween- 20 and $1 \%$ non-fat dry milk, and incubated with antibodies specific to S100A10 (Santa Cruz Biotechnology, Santa Cruz, CA, USA) and haptoglobin (Abcam, Cambridge, UK) at 1:1000 and 1:2000 dilutions, respectively. Anti-GAPDH (Tiangen, China) was used as endogenous loading control. Signals were visualized with a Phototope-HRP Western blot detection kit (Cell Signaling Technology, Danvers, MA, USA).

Immunohistochemistry. Formalin-fixed, paraffin-embedded tissue sections were deparaffinized, rehydrated, and then heated in $10 \mathrm{mmol} / \mathrm{l}$ citrate buffer $(\mathrm{pH} 6)$ for $10 \mathrm{~min}$ after washing in phosphate-buffered saline (PBS). After blocking endogenous peroxidase activity with a $3 \%$ aqueous $\mathrm{H}_{2} \mathrm{O}_{2}$ solution for $15 \mathrm{~min}$, the sections were incubated with the antihuman S100A10 protein rabbit polyclonal antibody (Santa
Cruz Biotechnology) at a dilutions of 1:25, and the anti-human haptoglobin rabbit polyclonal antibody (Protein Tech Group, Inc., Chicago, IL, USA) at dilutions of 1:10 for $60 \mathrm{~min}$ at room temperature. For each case, the primary antibody was replaced with PBS as a negative control. The EnVision+/DAB+ detection kit (Gene Tech, Shanghai, China) was used for the detection of the immunostaining.

\section{Results}

Quantitative comparison and identification of protein spots on 2-DE gels. Serum samples from 3 gallbladder cancer patients and 3 healthy volunteers were subjected to $2-\mathrm{DE}$ analysis. The gel image from the gallbladder cancer group was compared with that from the healthy volunteer group. Sixty-four differentially expressed protein spots that changed $>2$-fold were found from these two separate comparisons. The commonly differentially expressed spots were excised and subjected to in-gel tryptic digestion. Peptide masses were obtained using MALDI-TOF-MS. Identification of the differentially expressed protein spots are shown in Fig. 1 and summarized in Table I. Twenty-four proteins including S100A10, haptoglobin, cystatin-B, profilin-1 and superoxide dismutase were successfully identified. Twelve of these proteins were found overexpression in the gallbladder cancer patients. Quantitative comparison analysis of these proteins was shown that the expression difference between gallbladder cancer patients and healthy volunteers are $>2$-fold (Fig. 2). Among these proteins, two newly screened proteins, S100A10 and haptoglobin were subjected to further analyses.

Western blot analysis of S100A10 and haptoglobin proteins. To confirm the protein identification and differential expression of serum S100A10 and haptoglobin in gallbladder cancer patients, we conducted Western blotting using a new set of serum samples from gallbladder cancer patients and healthy volunteers. We found that the higher serum S100A10 and haptoglobin expression level in gallbladder cancer patients compare to that in health volunteer controls (Fig. 3).

S100A10 and haptoglobin protein expression by immunohistochemistry. We further analyzed the S100A10 and haptoglobin expression in formalin-fixed, paraffin-embedded tissues using immunohistochemistry. We collected 50 gallbladder cancer, 20 gallbladder adenoma, 20 normal gallbladder, 5 liver cholangiocarcinoma and 5 cholecystitis tissues at the Department of Pathology, the Second Affiliated Hospital of Suzhou University (Suzhou, China). The positive immunostaining of both S100A10 and haptoglobin were observed in the majority of gallbladder cancer cells, and localized to the cytoplasm and cell membrane (Fig. 4, left). The expression rate of S100A10 in gallbladder cancer was 90\% (45/50) and $66 \%$ (33/50), respectively (Table II). The expression of S100A10 and haptoglobin was mostly negative in gallbladder adenoma and normal gallbladder tissues (data not shown). The expression of S100A10 and haptoglobin and patients' clinicopathologic information was also evaluated. High expression of both S100A10 and haptoglobin were found in gallbladder cancer patients with late stage disease (III-V) $(\mathrm{P}=0.015$ and $\mathrm{P}<0.01)$, lymph node metastases $(\mathrm{P}=0.02$ and $\mathrm{P}<0.01)$ and short survival 
Table I. Differentially expressed proteins identified by MALDI-TOF-MS.

\begin{tabular}{lrrrrll}
\hline Spot & Mass & \multicolumn{1}{c}{ PI } & Coverage (\%) & Score & \multicolumn{1}{c}{ Proteon name } & Expression in cancer \\
\hline 15 & 10243 & 5.89 & 65 & 68 & Splicing factor 3B subunit 5 & $\uparrow$ \\
19 & 11190 & 6.96 & 61 & 78 & Cystatin-B & $\uparrow$ \\
26 & 11310 & 6.82 & 68 & 92 & S100A10 protein & $\uparrow$ \\
27 & 13912 & 10.31 & 41 & 65 & Histone H2B type 2-E & $\uparrow$ \\
172 & 15216 & 8.44 & 69 & 142 & Profilin-1 & $\uparrow$ \\
173 & 16564 & 5.07 & 45 & 80 & Eukaryotic translation initiation factor 1A & $\uparrow$ \\
174 & 17049 & 5.08 & 47 & 64 & Isoform 1 of eukaryotic translation & $\uparrow$ \\
& & & & & initiation factor 5A-1 & \\
280 & 31227 & 9.21 & 17 & 66 & FERM domain containing 3 & $\uparrow$ \\
296,323 & 31647 & 8.48 & 50 & 185 & Haptoglobin protein & $\uparrow$ \\
364 & 36201 & 8.57 & 38 & 91 & Glyceraldehyde-3-phosphate dehydrogenase & $\uparrow$ \\
708 & 25485 & 6.10 & 30 & 84 & Serum amyloid P-component precursor & $\uparrow$ \\
716 & 71317 & 7.11 & 14 & 108 & Harmonin isoform b3 & $\uparrow$ \\
267 & 30759 & 5.56 & 78 & 306 & Apolipoprotein A-I precursor & $\downarrow$ \\
179 & 19839 & 4.67 & 42 & 91 & Myosin regulatory light chain 2 & $\downarrow$ \\
191 & 20981 & 4.81 & 56 & 140 & Isoform 1 of protein canopy & $\downarrow$ \\
& & & & & homolog 2 precursor & $\downarrow$ \\
192 & 22993 & 6.51 & 44 & 114 & Proteasome subunit $\beta$ type-2 & $\downarrow$ \\
211 & 23250 & 5.87 & 52 & 111 & ARHGDIA & $\downarrow$ \\
225 & 24878 & 8.35 & 41 & 69 & Superoxide dismutase (Mn) & $\downarrow$ \\
343 & 33395 & 6.20 & 27 & 112 & Isoform 1 of Ficolin-3 precursor & $\downarrow$ \\
352 & 34465 & 5.71 & 31 & 91 & a-2-glycoprotein 1, zinc & $\downarrow$ \\
384 & 38940 & 6.13 & 34 & 116 & HP haptoglobin isoform 2 preproprotein & $\downarrow$ \\
404 & 39603 & 5.27 & 55 & 170 & CD5 antigen-like precursor & $\downarrow$ \\
428 & 58537 & 6.24 & 22 & 77 & CLU clusterin isoform & $\downarrow$ \\
447,458 & 71194 & 5.43 & 12 & 88 & ITIH4 71 kDa protein & $\downarrow$ \\
\hline
\end{tabular}

period ( $\mathrm{P}=0.02$ and 0.005 , respectively) (Table II). The expression of S100A10 and haptoglobin in liver cholangiocarcinoma and cholecystitis tissues were negative (Fig. 4, middle and right).

\section{Discussion}

Serum is an ideal diagnostic specimen in general, due to its easy and inexpensive accessibility (10). It would be valuable if a sensitive and specific biomarker can be detected in serum, and can be used clinically for screening and early diagnosis of cancer. The 2-DE has been traditionally used to identify the protein expression differences in serum, saliva and tissue specimens. These proteins can be subsequently identified by mass spectrometry (11). In recent years, the rapid development of proteomics technologies has provided new technology platforms for identifying new tumor biomarkers, in which 2-DE-based comparative proteomic analysis has been applied successfully to screen potential biomarkers for many cancers, especially for cancer screening and early diagnosis (4-7). The present study was planned to identify new serum biomarkers using 2-DE and MALDI-TOF-MS for the early detection of gallbladder cancer.

In the current study, we successfully identified a total of 24 differentially expressed proteins, including 12 up-regulated proteins and 12 down-regulated proteins, between gallbladder cancer patients and healthy cancer-free controls, This is the first study in Chinese population using proteomic-based analysis for serum biomarkers identification in gallbladder cancer. Some of the up-regulated proteins in gallbladder cancer, such as splicing factor $3 \mathrm{~B}$ subunit 5 , cystatin-B, S100A10 protein, histone H2B type 2-E, profilin-1, eukaryotic translation initiation factor $1 \mathrm{~A}$, isoform 1 of eukaryotic translation initiation factor 5A-1, FERM domain containing 3, glyceraldehyde-3-phosphate dehydrogenase, serum amyloid P-component precursor, harmonin isoform b3, were firstly identified in gallbladder cancer. Among which, two up-regulated proteins S100A10 and haptoglobin were further validated in gallbladder cancer samples. Using Western blotting, we demonstrated elevated protein levels of S100A10 and haptoglobin protein in gallbladder cancer compared with healthy volunteer controls. We further enriched the study by including liver cholangiocarcinoma and cholecystitis in immunohistochemical study and confirmed that S100A10 and haptoglobin are exclusively expressed in gallbladder cancer. In this study, all of the patients with gallbladder cancer had a small, surgically resectable tumor, suggesting that the differentially expressed proteins can be potentially used as biomarkers for the early diagnosis of gallbladder cancer. 

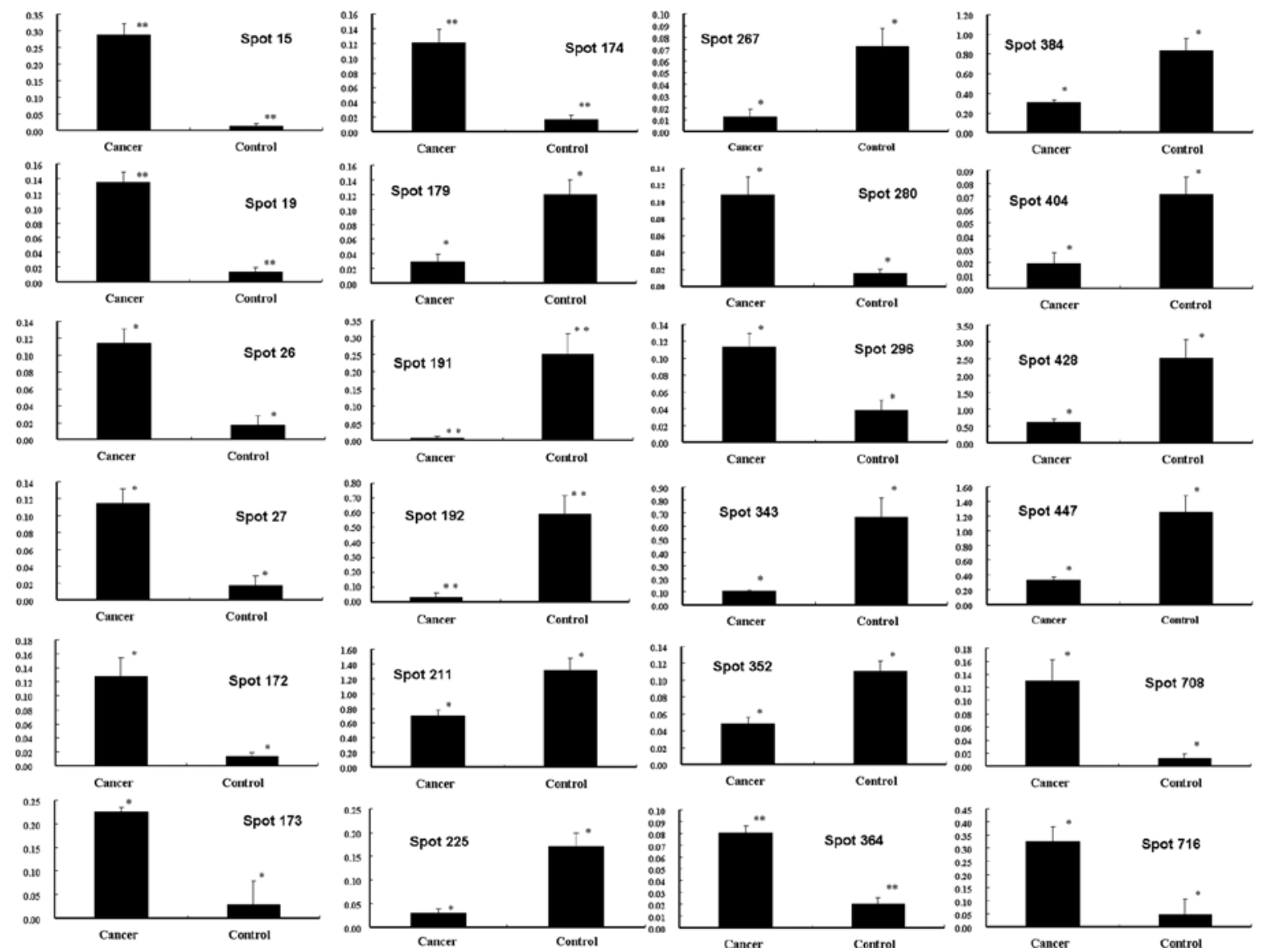

Figure 2. Quantitative comparisons of the 24 differentially expressed protein spots in serum from gallbladder cancer patients and healthy volunteers. The volume of spots was normalized and quantified as relative intensity by Image Master 2D Software. The spot numbers used here are the same as those in Table I. Error bars represent mean $\pm \mathrm{SD} .{ }^{*} \mathrm{P}<0.05,{ }^{* *} \mathrm{P}<0.01$.

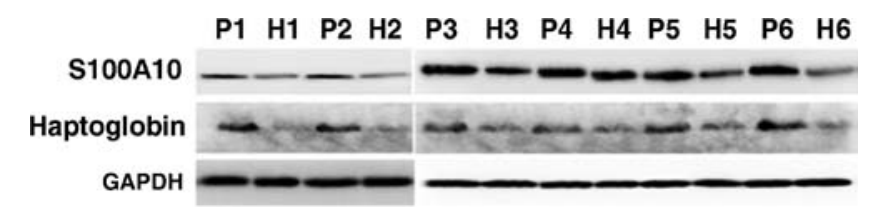

Figure 3. Expression of S100A10 and haptoglobin proteins in serum samples. Serum samples from gallbladder cancer patients and healthy volunteers were subject to Western blotting. Higher expression level of haptoglobin and S100A10 was shown in gallbladder cancer patients than that of healthy volunteers. Equivalence of loading protein is shown by anti-GAPDH labeling. $\mathrm{P}$, patient; $\mathrm{H}$, healthy volunteers.

The S100 protein (SP) family includes more than 20 members, all of which are identified only in vertebrates, sharing a common structure, the $\mathrm{Ca}^{2+}$-binding EF-hand motif $(12,13)$. SPs are multifunctional signaling proteins involved in numerous cellular functions, such as protein phosphorylation, enzyme activation, interaction with cytoskeletal components and calcium homeostasis (14). Moreover, SPs regulate many cellular processes such as cell growth, cell cycle progression, differentiation, transcription and secretion (15). Overexpression of several SPs has been reported in different stages and types of human tumors, such as anaplastic large cell lymphoma (16), uterine smooth muscle tumors (17), breast cancer (18), thyroid adenomas and carcinomas (19), invasive squamous cell carci- noma of the uterine cervix, serous adenocarcinoma of the ovary and invasive breast carcinoma (20). The overexpression of SPs in tumors suggests their potential role in tumorigenesis (21). It has been reported that siRNA-mediated down-regulation of S100A10 gene expression in colorectal cancer cells resulted in a large decrease the extracellular S100A10 protein and correlated with $45 \%$ loss of plasminogen binding, $65 \%$ loss of cellular plasmin generation and complete loss of plasminogendependent cellular invasiveness, suggested the role of S100A10 in the initiation and development of cancer (22). Our data showed that S100A10 overexpression in gallbladder cancer, suggesting that S100A10 may have potential value as a diagnostic marker and therapeutic target for gallbladder cancer, but needs further investigation.

Haptoglobin is classified as an acute-phase protein. The blood haptoglobin level increases in patients with inflammation, tissue damage, infection and certain cancers (23). However, haptoglobin levels decreases in hemolytic conditions, as a result of its role in clearing free hemoglobin from the blood stream. The major site of haptoglobin biosynthesis is liver and its expression level is regulated by several cytokines, including IL-1, IL- 6 , TNF- $\alpha$ and TGF- $\beta$ (24). Previous studies have demonstrated that elevated haptoglobin level in the serum, as well as alterations in the degree and pattern of glycan adducts, are associated with a variety of cancers including gallbladder cancer (25-27). The causes of these changes may vary and 


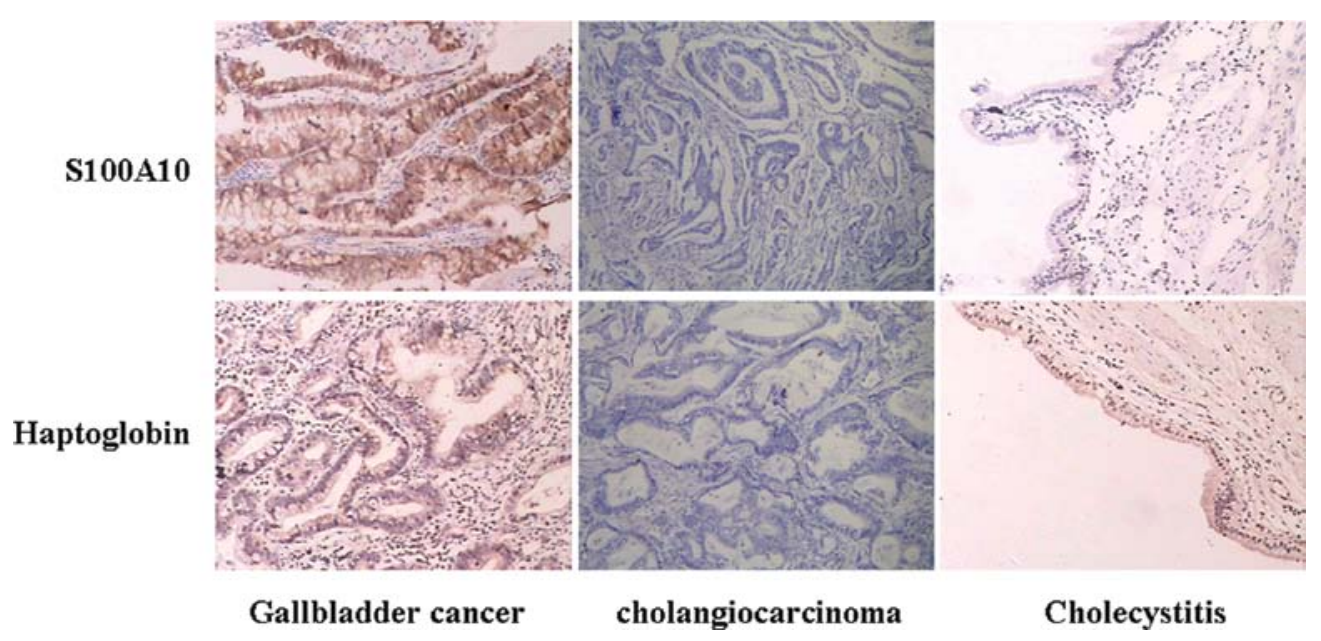

Figure 4. Immunohistochemical staining of S100A100 and haptoglobin in formalin-fixed, paraffin-embedded tissues. Strong positive staining of S100A10 and haptoglobin were shown in gallbladder cancer (left) and negative staining were shown in liver cholangiocarcinoma (middle) and cholecystitis tissue (right), as indicated.

Table II. Correlation between S100A10 and haptoglobin expression and clinicopathological factors in 50 gallbladder cancer patients.

\begin{tabular}{|c|c|c|c|c|c|}
\hline Factors & $\begin{array}{l}\text { No. of } \\
\text { patients }\end{array}$ & $\begin{array}{c}\text { Patients with S100A10 } \\
\text { expression (\%) }\end{array}$ & P-value & $\begin{array}{l}\text { Patients with haptoglobin } \\
\text { expression }(\%)\end{array}$ & P-value \\
\hline \multicolumn{6}{|l|}{ Age (years) } \\
\hline$<60$ & 20 & $18(90)$ & \multirow[t]{2}{*}{0.63} & $10(50)$ & \multirow[t]{2}{*}{0.05} \\
\hline$\geq 60$ & 30 & $27(90)$ & & $23(76.7)$ & \\
\hline \multicolumn{6}{|l|}{ Gender } \\
\hline Male & 18 & 16 (88.9) & \multirow[t]{2}{*}{0.77} & $11(61.1)$ & \multirow[t]{2}{*}{0.58} \\
\hline Female & 32 & $29(90.6)$ & & $22(68.8)$ & \\
\hline \multicolumn{6}{|l|}{ Gallstones } \\
\hline Absent & 25 & $24(96)$ & \multirow[t]{2}{*}{0.35} & $18(72)$ & \multirow[t]{2}{*}{0.37} \\
\hline Present & 25 & $21(84)$ & & $15(60)$ & \\
\hline \multicolumn{6}{|l|}{ Nevin stage } \\
\hline I-II & 7 & $4(57.1)$ & \multirow[t]{2}{*}{0.015} & $1(14.3)$ & \multirow[t]{2}{*}{$<0.01$} \\
\hline III-V & 43 & $41(95.3)$ & & $32(74.4)$ & \\
\hline \multicolumn{6}{|c|}{$\begin{array}{l}\text { Lymph node } \\
\text { metastasis }\end{array}$} \\
\hline Absent & 20 & $15(75)$ & \multirow[t]{2}{*}{0.02} & $8(40)$ & \multirow[t]{2}{*}{$<0.01$} \\
\hline Present & 30 & $30(100)$ & & $25(83.3)$ & \\
\hline \multicolumn{6}{|c|}{$\begin{array}{l}\text { Survival time } \\
\text { (years) }\end{array}$} \\
\hline$<1$ & 31 & $29(93.5)$ & \multirow[t]{2}{*}{0.02} & $25(80.6)$ & \multirow[t]{2}{*}{0.005} \\
\hline$\geq 1$ & 19 & $12(63.2)$ & & 7 (36.8) & \\
\hline
\end{tabular}

may involve in the host-defense and other tumor-promoting mechanisms. Previous study demonstrated the proapoptotic activity of haptoglobin toward hepatocarcinoma cells in culture, provided the evidence of a host-defense mechanism (28). In addition, the importance of the Sialyl-Lewis X determined in cell adhesion suggests that abnormal haptoglobin glycosylation could interfere with tumor invasion and/or metastasis (29). Haptoglobin has also been shown to be a proangiogenic factor suggesting that elevated haptoglobin can stimulate tumor angiogenesis as well (30).

Gallbladder cancer is the most common malignant tumor of the biliary tract worldwide. However, the early diagnosis of gallbladder cancer remains challenging.

The present study clear shows that combined 2-DE and MALDI-TOF-MS comparative proteomic analysis can identify potential serum biomarker in gallbladder cancer. We 
successfully identified 24 unique proteins, including several novel proteins. Majority of the identified proteins have not been previously described in gallbladder cancer. Our data also suggested that some candidate proteins such as S100A10 and haptoglobin may serve as potential biomarkers for early detection of gallbladder cancer and may be of use in the therapeutic intervention for gallbladder cancer in the future, but needs further validation in large number of patient samples. Functional analysis of these proteins is also one of the subjects of ongoing investigation in our laboratory.

\section{References}

1. Lai EC and Lau WY: Aggressive surgical resection for carcinoma of gallbladder. ANZ J Surg 75: 441-444, 2005.

2. Bartlett DL, Fong Y, Fortner JG, Brennan MF and Blumgart LH: Long-term results after resection for gallbladder cancer. Ann Surg 224: 639-646, 1996

3. D'Souza M, Joshi A, Desai D, Abraham P, Bhaduri A and Shah S: Highly elevated CA19-9 and gall bladder mass do not add up to cancer. Indian J Gastroenterol 25: 271-272, 2006.

4. Tseng MY, Liu SY, Chen HR, et al: Serine protease inhibitor (SERPIN) B1 promotes oral cancer cell motility and is overexpressed in invasive oral squamous cell carcinoma. Oral Oncol 45: 771-776, 2009.

5. Wang X, Chen Y, Han QB, et al: Proteomic identification of molecular targets of gambogic acid: role of stathmin in hepatocellular carcinoma. Proteomics 9: 242-253, 2009.

6. Chen JH, Ni RZ, Xiao MB, Guo JG and Zhou JW: Comparative proteomic analysis of differentially expressed proteins in human pancreatic cancer tissue. Hepatobiliary Pancreat Dis Int 8 : 193-200, 2009

7. Liu YF, Xiao ZQ, Li MX, et al: Quantitative proteome analysis reveals annexin $\mathrm{A} 3$ as a novel biomarker in lung adenocarcinoma. J Pathol 217: 54-64, 2009.

8. Zhu YF, Cui YG, Guo XJ, et al: Proteomic analysis of effect of hyperthermia on spermatogenesis in adult male mice. J Proteome Res 5: 2217-2225, 2006.

9. Feng JT, Liu YK, Song HY, et al: Heat-shock protein 27: a potential biomarker for hepatocellular carcinoma identified by serum proteome analysis. Proteomics 5: 4581-4588, 2005.

10. Chen R, Pan S, Brentnall TA and Aebersold R: Proteomic profiling of pancreatic cancer for biomarker discovery. Mol Cell Proteomics 4: 523-533, 2005.

11. Latterich M, Abramovitz M and Leyland-Jones B: Proteomics: new technologies and clinical applications. Eur J Cancer 44 2737-2741, 2008

12. Marenholz I, Lovering RC and Heizmann CW: An update of the S100 nomenclature. Biochim Biophys Acta 1763: 1282-1283, 2006.

13. Marenholz I, Heizmann CW and Fritz G: S100 proteins in mouse and man: from evolution to function and pathology (including an update of the nomenclature). Biochem Biophys Res Commun 322 : $1111-1122,2004$.
14. Donato R: Intracellular and extracellular roles of S100 proteins Microsc Res Tech 60: 540-551, 2003.

15. Salama I, Malone PS, Mihaimeed F and Jones JL: A review of the S100 proteins in cancer. Eur J Surg Oncol 34: 357-364, 2008.

16. Rust R, Visser L, van der Leij J, et al: High expression of calcium-binding proteins, S100A10, S100A11 and CALM2 in anaplastic large cell lymphoma. Br J Haematol 131: 596-608, 2005.

17. Kanamori T, Takakura K, Mandai M, et al: Increased expression of calcium-binding protein S100 in human uterine smooth muscle tumours. Mol Hum Reprod 10: 735-742, 2004.

18. Luo RC, He XB, Cai HB and Li AM: Detection of serum S100 protein and tissue polypeptide-specific antigen for diagnosis and treatment of breast cancer. Di Yi Jun Yi Da Xue Xue Bao 24: 102-104, 2004.

19. Torres-Cabala C, Panizo-Santos A, Krutzsch HC, et al: Differential expression of S100C in thyroid lesions. Int J Surg Pathol 12: 107-115, 2004

20. Cross SS, Hamdy FC, Deloulme JC and Rehman I: Expression of S100 proteins in normal human tissues and common cancers using tissue microarrays: S100A6, S100A8, S100A9 and S100A11 are all overexpressed in common cancers. Histopathology 46: 256-269, 2005

21. Emberley ED, Murphy LC and Watson PH: S100 proteins and their influence on pro-survival pathways in cancer. Biochem Cell Biol 82: 508-515, 2004.

22. Zhang L, Fogg DK and Waisman DM: RNA interference-mediated silencing of the S100A10 gene attenuates plasmin generation and invasiveness of Colo 222 colorectal cancer cells. J Biol Chem 279: 2053-2062, 2004.

23. Dobryszycka W: Biological functions of haptoglobin - new pieces to an old puzzle. Eur J Clin Chem Clin Biochem 35: 647-654, 1997.

24. Baumann H, Jahreis GP and Morella KK: Interaction of cytokine and glucocorticoid-response elements of acute-phase plasma protein genes. Importance of glucocorticoid receptor level and cell type for regulation of the elements from rat alpha 1-acid glycoprotein and beta-fibrinogen genes. J Biol Chem 265: 22275-22281, 1990.

25. Ang IL, Poon TC, Lai PB, et al: Study of serum haptoglobin and its glycoforms in the diagnosis of hepatocellular carcinoma: a glycoproteomic approach. J Proteome Res 5: 2691-2700, 2006.

26. Krueger KE and Srivastava S: Posttranslational protein modifications: current implications for cancer detection, prevention, and therapeutics. Mol Cell Proteomics 5: 1799-1810, 2006.

27. Hudson LD and Enck RE: Hyperhaptoglobinemia and carcinoma of the gallbladder. Am J Gastroenterol 71: 284-286, 1979.

28. Kim IK, Lee JH, Kim HS, Kwon OJ and Shim BS: A novel function of haptoglobin: haptoglobin-haemoglobin complex induces apoptosis of hepatocarcinomatous Hep 3B cells. Scand J Clin Lab Invest 55: 529-535, 1995.

29. Kannagi R, Izawa M, Koike T, Miyazaki K and Kimura N: Carbohydrate-mediated cell adhesion in cancer metastasis and angiogenesis. Cancer Sci 95: 377-384, 2004.

30. Fosslien E: Review: molecular pathology of cyclooxygenase-2 in cancer-induced angiogenesis. Ann Clin Lab Sci 31: 325-348, 2001. 